Universidad de Lima

Facultad de Comunicación

Carrera de Comunicación

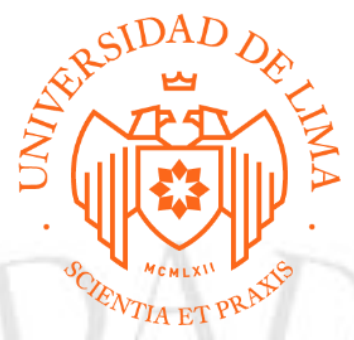

\title{
CANALES WEB HD - CANAL BCP -
} AMERICA TV

Trabajo de Suficiencia Profesional para optar el Título Profesional de Licenciado en Comunicación

\section{Orlando de la Flor Arbulú}

Código 19742351

\author{
Asesor \\ Carlos Rivadeneyra Olcese
}

Lima - Perú

Julio de 2019 


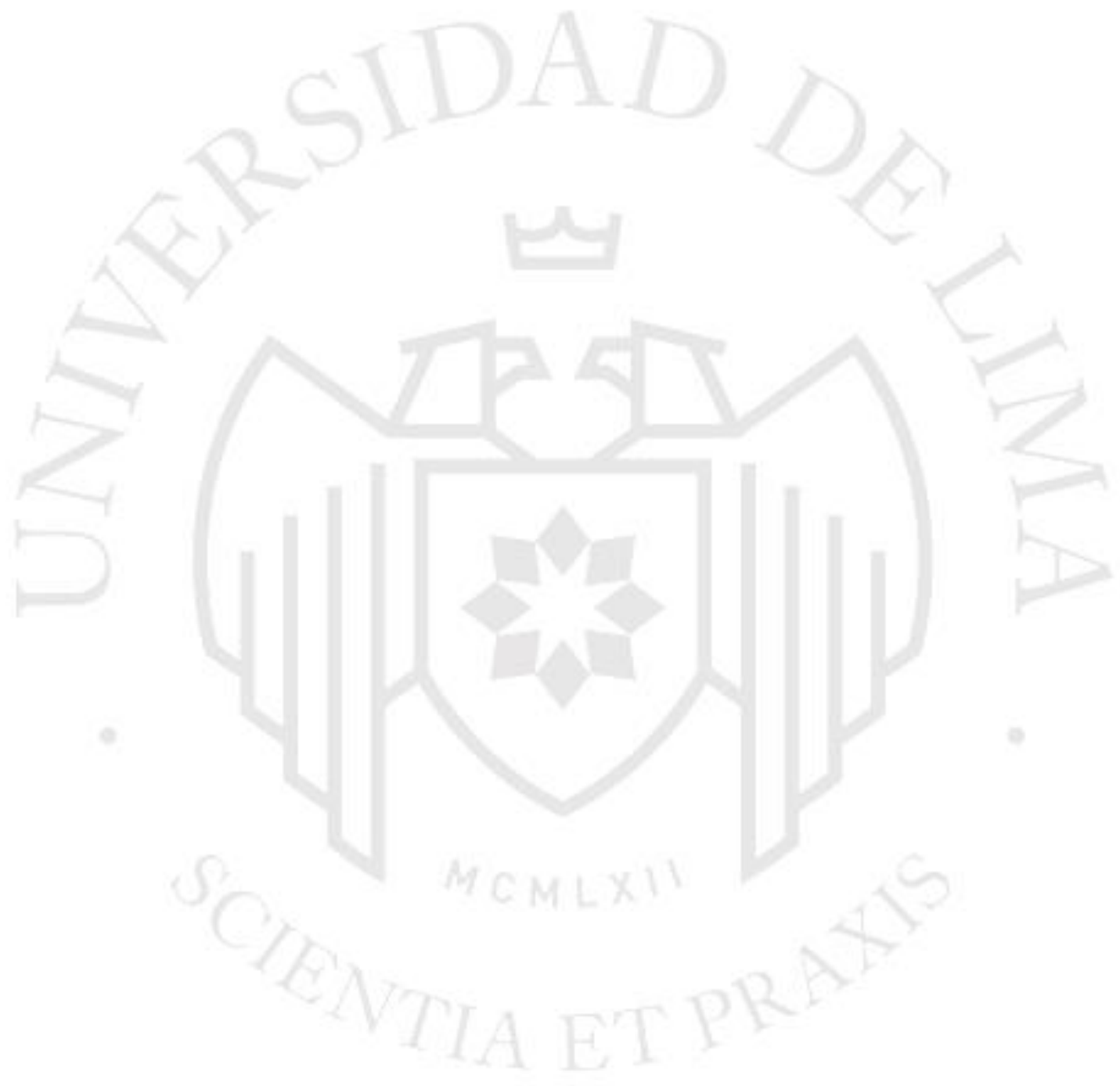


CANALES WEB HD - CANAL BCP AMERICA TV 


\section{ÍNDICE}

RESUMEN 06

INTRODUCCIÓN

\section{EXPERIENCIA PROFESIONAL}

1.1 Productor y Director de AMÉRICA TV 08

1.2 Productor y Director de videos Canal BCP 09

1.3 Los canales Web HD por internet 10

\section{COMPETENCIAS PROFESIONALES}

2.1 Canal BCP 12

2.1.1 Objetivos de Canal BCP 12

2.1.2 Diferentes tipos de televisión 12

2.1.2.1 La televisión de señal abierta 12

2.1.2.2 Los circuitos cerrados y su función 14

2.1.2.3 La televisión y sus aplicaciones $\quad 16$

2.1.3 Diseño del Proyecto 18

2.1.3.1 Análisis de necesidades $\quad 19$

2.1.3.2 Naturaleza del medio 19

2.1.3.3 Potencialidades 19

2.1.3.4 Limitaciones 20

2.1.3.5 Características de la audiencia 21

2.1.3.6 Servicios sociales 22

2.1.3.7 Propósitos del emisor $\quad 23$

2.1.3.8 Información de productos 23

2.1.4 Diseño de identidad para canal BCP 25

2.1.4.1 Descripción del sistema 25

2.1.4.2 Sistema técnico: hardware 27

2.1.5 La programación 30

2.1.5.1 La recepción: consideraciones básicas 30

2.1.5.2 Aula virtual 32

2.1.6 La producción $\quad 32$

2.1.7 Conclusiones 33

2.1.7.1 Descripción del caso 33

2.1.7.2 Resultados obtenidos $\quad 33$

2.1.7.3 Materiales producidos $\quad 34$

2.2 Proyecto Canal Web HD 35

2.2.1 Objetivos de Canal web HD 35

2.2.2 Descripción del caso 35

2.2.3 Características $\quad 35$

2.2.4 Beneficios 36

2.2.5 Implementación del canal Web: Gantt $\quad 36$

2.2.6 Equipamiento técnico para Estudio de TV Web 37

2.2.7 Resultados obtenidos $\quad 40$ 
2.2.8 Materiales producidos

3. REFLEXIONES PROFESIONALES

41

4. RECOMENDACIONES A LOS EGRESADOS

BIBLIOGRAFÍA 


\section{RESUMEN}

Cuando tu único fin es Comunicar, no importa los riesgos y obstáculos que encuentres, Esfuerzo; es así que en esta larga trayectoria vivencial, donde se aplica lo aprendido y experimentas lo vivido, Paciencia, se pone en práctica la TELEVISION en todas sus características Logro, tiempos, espacio, uso, en lo antiguo y lo moderno, generando la necesidad de plataformas digitales, siempre con un único fin de innovar, crecer, informar, entretener, satisfaciendo al cliente, Dedicación.

Palabras clave: televisión, producción de televisión, dirección de televisión, televisión streaming.

\section{ABSTRACT}

When your sole purpose is to communicate No matter the risks and obstacles you encounter; It is so that in this long experiential trajectory, where the learned and the experience is applied. The television is put into practice in all its characteristics use and space in the old and the modern time, generating the need for digital platforms, Always with a single purpose of innovating, growing, informing, entertaining and satisfying the client and the viewer.

Keywords: television, television production, television direction, television streaming. 


\section{INTRODUCCION}

Inmersos en un mundo dinámico, de constantes avances tecnológicos, el perfil del egresado de la Facultad de Comunicación interviene en la dirección creativa de proyectos públicos y privados, teniendo como base la investigación y la innovación. En ese marco analiza, comprende, desarrolla, gestiona y lidera productos comunicativos de alta calidad con responsabilidad y sentido ético.

Bachiller en comunicación, graduado en el año 2005, hoy en día con la única visión de obtener el título de Licenciado en Comunicación bajo la modalidad de Trabajo de Suficiencia Profesional, con el único propósito de heredar mis conocimientos y experiencias adquiridas a mis hijos, mi familia y a cuanto comunicador le apasione nuestra profesión: COMUNICAR.

Hoy, donde muchos millenials han captado la máxima atención en las redes sociales como influencers, Youtubers y otros; nuestra forma de comunicar es distinta, debemos llegar de manera rápida, ágil y simple a nuestro público objetivo, para que el cliente pueda lograr captar la atención de su consumidor creando plataformas web canales web HD que interactúen con la información que se le brinda al público en general, obteniendo en tiempo real algún mensaje o acontecimiento via streaming (viaje por la nube) desde tu celular, Tablet o pc el mismo que se puede compartir innumerables veces, permitiendo tener una gran concurrencia de usuarios que pueden viralizar el contenido.

Hace muchos años atrás, había un proceso de transformación escalonada, primero en América TV, cuya emisión tenía una señal abierta, en vivo, grabada y editada en cintas U-matic o Ampex 2 pulgadas para luego pasarla al cable, señal emitida en tv cerrada por fibra óptica con canales segmentados, ahora la tv web HD se emite por internet al mundo por las redes sociales en vivo y digitalizada al PC y a los celulares se graba en tarjetas. este cambio lo viví durante casi 40 años de tv, toda una transformación a lo digital. 


\section{EXPERIENCIA PROFESIONAL}

Especialista en Imagen Institucional con 40 años de experiencia, Productor de los principales canales de TV (América Televisión y ATV), creador de la programación original de Cable Mágico (CMC, CMN, CMD) y de los sistemas de comunicación "below the line" de circuito cerrado del BCP. La experiencia incluye también la dirección y producción de innumerables comerciales para entidades públicas y privadas y decenas de programas de televisión de diverso tipo, como novelas, series, programas políticos, deportivos, de concursos y especiales musicales internacionales.

Actualmente Gerente General de Visionaria SAC y Visionaria TV. Creador de los Canales Web HD onpe.tv, usil.tv, miratv.pe, sunat.tv, entre otros. En cada una de estas plataformas comunicacionales se ha organizado la configuración, programación y armado de los equipos técnicos a utilizar para los canales de cable, creando la programación y contenido de los mismos. (Enero 2009 y Agosto 2019).

\subsection{Productor y Director de AMÉRICA TV - Canal 4: 1979-1989}

Dirección de programas políticos, musicales, especiales, deportivos, entre otros. Durante el periodo de 1979 al 1989. Participó en reconocidos programas que llegaron a obtener alto rating y aceptación del público televidente, y estos son:

- Hola Yola

- La máquina del rock

- Visión Hildebrandt

- Voz y Voto Manuel D’Ornellas

- Los detectilocos

- Hello America

- La llegada del papa Juan Pablo II

- Olimpiadas Seúl 1988

Entre otros

En cada uno de estos programas se realizaba la investigación de los temas a tratar en favor al público consumidor, selección del animador y/o presentador idóneo en un casting exhaustivo, que tuviera las cualidades precisas para la conducción del programa. Posterior a esta selección se generaba reuniones de coordinación para la revisión de los mensajes o frases a decir, vestuario, utilería, escenografía. Para realizar un programa de tv primero se estructura la idea creativa, selecciones de personajes, equipamiento técnico para que este pueda salir en vivo como cámaras, trípodes, switcher 
una consola de audio, micrófonos, boom, asistentes de cámara, producción, luminito, sonidista, islas de edición, editores.

Por ejemplo América Roller, fue un programa donde la fiebre de los patines jugó un papel muy importante, se locacionó en las pistas de patinaje escogiendo un elenco de chicas y chicos patinadores y produciendo un programa muy éxito, que duro varios años y se emitía por América los sábados por la tarde, grabándose a los patinadores bailando con los patines diferentes canciones éxitos musicales y creaba historias teatralizadas con los del elenco como por ejemplo Romeo y Julieta, ellos actuaban en el estudio o en diversas locaciones que se tenían, todo este material grabado con unidad móvil lo editaba y post producía y armaba todas las semana un programa de 48 minutos que tenía 4 cortes comerciales de tres minutos, ahí se lograba la hora de tv.

Dirigiendo en estudio y exteriores las cámaras, la iluminación, creación de la escenografía, vestuario, maquillaje, etc. era todo un equipo de técnicos que trabajaban cada programa en el aspecto creativo de producción, de grabación y edición hasta llegar a su emisión desde el control maestro en una cinta u-matic de 60 minutos y en la fecha ya programada.

\subsection{Productor y Director de Videos Canal BCP: 2000 - 2014}

Cable Canal de Televisión: CCTV Banco de Crédito del Perú. Al adquirir una amplia experiencia en los canales de televisión, se dio la oportunidad de producir el contenido de los CCTV del Banco de Crédito del Perú en sus oficinas del 2000 al 2014. Generando así, una experiencia como creador y productor de los videos.

Una vez puesto en marcha el sistema de CCTV del BCP, se creó diferentes contenidos según las campañas que se tenía en ese momento, un porcentaje de material era del Banco, otro de cultura, entretenimiento y deportes, que se dividían a lo largo de los 45 minutos que duraba el Reel, el que se loopeaba dando vueltas durante la atención diaria del Banco en todas sus oficinas a nivel nacional, cada video tenía 2 minutos de duración, una programación muy variada para el tele paciente así como el público en general.

Un ejemplo era el segmento La Receta del Mes con Alfredo Aramburú, grabada en el restaurante Alfresco, 5 recetas en un día, 
se editaba y se cargaban al Reel de programación del Banco, este segmento tuvo mucha acogida ya que los clientes anotaban las recetas.

Las diferencias entre Tv masiva y Cctv son muchas, ya que es otro formato, otro tiempo, otra audiencia, otro tratamiento, son públicos objetivos diferentes, justamente su nombre lo dice TELEVISION ABIERTA, contenido variado para todo el público en general y LOS CIRCUITOS CERRADOS DE TELEVISION contenido de una programación limitada a los usuarios que visiten o se encuentren en el lugar que se emite. En este sin fin de videos informativos segmentados según público usuario que mantenía el $\mathrm{BCP}$, el mismo que día a día lograba captar la acogida del público consumidor, creando historias reales o cotidianas que hicieran que el público se identifique con los mismos, realizando actividades de descentralización en cada una de las sedes a nivel nacional, ejecutando la dirección de grabaciones a personajes ilustres y de gran trayectoria que se han ido mostrando a lo largo de todo este tiempo.

\subsection{Los canales Web HD por internet: 2009 - 2019}

En este nuevo siglo, donde el internet paso a convertirse en una nueva plataforma de emisión de contenidos audiovisuales al mundo del día a día, es que se lidera la creación y configuración de los canales Web HD como Gerente general en VISIONARIA SAC, realizando también la dirección y producción de comerciales, documentales, programas de $T V$, canales web $H D$, diseño y creación de contenidos, para entidades públicas y privadas, como por ejemplo:

www.miratv.pe - Canal Web de la Municipalidad de Miraflores www.sunat.tv - Canal Web de la SUNAT

www.canal-uni.tv - Canal de la Universidad de Ingeniería del Perú www.inictel-uni.tv. - Canal de INICTEL

Transmisiones en Vivo de eventos para el Fondo Monetario Internacional en 2015 y el Banco Mundial en 2016, Elecciones Municipales Presidenciales 2016, Elecciones Regionales 2017, entre otros, durante el periodo de 2009 a la actualidad.

Hoy en día se ha ampliado más el horizonte, pues el canal de señal abierta y circuito cerrado, se ha unificado y mejorado, pues ahora 
lo tienes a tu alcance en el punto donde te encuentres, obteniendo así los Canales Web, pudiendo verlo no solo en tu tv convencional o televisores de cctv si no en tu pc, celular y tablets, desde cualquier parte del mundo, a diferencia de la tv abierta que solo se veía en una televisión en la sala de la casa, ahora esta señal ya se sumó al mundo web, así también los cctv ya se pueden emitir vía internet con un canal web HD y bajar esta señal en cada oficina del banco, empresa y/o comercio que lo tenga ya que permite hacer transmisiones en vivo vía streaming, capacitaciones, por lo que vemos que la internet logra integrar a todos los sistemas anteriores de televisión con lo que hoy estamos encaminados a la tv selectiva $y$, cada aspecto de la vida tendría su propio medio para difundir su contenido. 


\section{COMPETENCIAS PROFESIONALES}

\subsection{PROYECTO CANAL BCP}

\subsubsection{Objetivos de Canal BCP}

\section{Objetivo general}

- Se diseñó el Sistema de Circuito Cerrado -CCTV de atención al público en las agencias del Banco de Crédito del Perú a nivel nacional llamado Servimatic - Canal BCP

\section{Objetivos específicos}

- Acoger de manera ordenada y entretenida al público asistente al Banco quienes esperaban turno de atención en las ventanillas, con una programación de videos variados configurados en el sistema cctv de atención al público en las agencias del Banco de Crédito del Perú a Nivel Nacional llamado Servimatic - Canal Bcp

- CCTV: Circuito Cerrado de Televisión, es un contenido audiovisual digitalizado o cargado a una pc que se difunde por un monitor o varios monitores en una locación, teniendo un tiempo de duración en loop que se repite a lo largo de la atención diaria al público en la institución

\subsubsection{Diferentes tipos de televisión}

\subsubsection{La televisión de señal abierta}

La televisión comercial privada y estatal en el Perú llega a finales de la década del cincuenta, sustentada por la publicidad en el caso de los canales privados y en el caso del estado, como un servicio del Ministerio de Educación. Fueron dos modelos de organización.

El canal del estado decayó al convertirse en una oficina burocrática al servicio de la publicidad de los gobiernos de turno. Los canales privados de señal abierta, también han tenido períodos de crisis, sea por la intervención del estado o por la propia gestión de sus propietarios.

Todos hemos sido testigos de lo ocurrido en la última década. Es el poder de los medios, lo que se pone en la balanza política. Es un universo complicado, 
complejo que genera a su vez mucho dinero. Los comunicadores sociales que hemos laborado en los canales privados de señal abierta, sabemos las posibilidades y las limitaciones que tienen.

¿Qué otras posibilidades tienen los comunicadores sociales?. Abrir otros campos, marcar rumbos diferentes, desarrollar experiencias novedosas y referidas a objetivos funcionales, coherentes, eficaces. La creatividad no tiene límites, menos aún cuando el desarrollo tecnológico permite plantear y expandir nuevas formas de integración a los múltiples caminos de la globalización.

En el ejercicio profesional del Comunicador Social se presentan diferentes retos, con sus respectivos grados de dificultad. Parte del trabajo es enfrentarse a los retos y resolver creativamente las limitaciones y dificultades de cualquier proyecto comunicativo.

El espacio laboral del Comunicador es muy amplio y siempre cada experiencia es enriquecedora. Los aprendizajes son permanentes y ello implica una mayor seguridad para asumir nuevos proyectos. Pero hay algo que a veces se pierde de vista en el trabajo: la base de conocimientos y vivencias que la formación académica ha aportado al comunicador.

En el caso del Proyecto que presento para la obtención del Título Profesional, como en otros proyectos en los que he participado, siempre están presentes tales bases.

El Proyecto que presento, se encuentra en plena vigencia operativa y - lo que es muy importante - se ha convertido en un instrumento de trabajo imprescindible para la empresa para la que fue diseñado. $Y$ el modelo que se diseño, ha sido copiado por otras empresas, ampliando la base laboral para nuevos comunicadores en el campo de la publicidad segmentada.

Es verdad que el Proyecto ha tenido varias etapas en su ejecución, pero es en este momento que ha alcanzado su pleno desarrollo. Ha sido un proceso largo, pero cada nueva etapa ha significado un avance cada vez mayor. Ciertamente la eficacia de un proyecto comunicativo demuestra el cuidado en el diseño, la planificación operativa sustentada en el análisis permanente de las necesidades de los usuarios y los propósitos de la empresa. Podríamos decir que se trata de un Proyecto vivo, vigente y de calidad. El resultado de todos estos elementos es su eficacia. Un proyecto mal diseñado, sin planificación, sin cuidado, atendiendo sólo a la inmediatez o a la coyuntura, está condenado a la futilidad o directamente al fracaso, arrastrando también al equipo profesional que lo elaboró.

Creatividad, lucidez, inteligencia, conocimientos, disciplina, liderazgo, trabajo multidisciplinario, son los componentes esenciales para el éxito laboral en el campo de la Comunicación Social. Por el contrario, la inmediatez, la indisciplina, la ausencia de creatividad, la incapacidad de trabajar en equipo, conducen al inmovilismo social y al paro laboral. 
La propuesta trata de un Proyecto articulado en la experiencia de haber trabajado en la producción de programas de varios canales de señal abierta, en la elaboración del montaje técnico de la televisión por cable (Cable Mágico) y en la producción y realización de mensajes publicitarios en otras productoras y luego en mi propia productora. Toda esta experiencia ha sido muy útil para el diseño técnico y la Producción para el Canal BCP y la televisión de circuito cerrado.

\subsubsection{Los circuitos cerrados y su función}

Es necesario señalar los elementos que diferencian la señal abierta y circuitos cerrados de televisión. Hay algunos elementos comunes entre ambos sistemas, como los modos de producción y los lenguajes mediáticos. Sin embargo, sólo señalaremos los elementos diferenciales.

El primer aspecto se refiere a las "formas de emisión". La señal abierta se transmite a partir de un transmisor y una antena que lanza señales codificadas a través de ondas hertzianas que viajan en el éter hasta un "sistema de recepción" que decodifica las señales y las convierte en imágenes de televisión.

Los circuitos cerrados no viajan por el espacio sino por cables conectados desde el punto de distribución hasta las terminales de recepción (los televisores). Otra forma de emisión es encapsular las señales de video en un soporte electromagnético o digital y luego recuperar la información en equipos de lectura y reconversión (Antes era el VHS y ahora el CD).

El segundo aspecto se refiere a "las formas de recepción". En el caso de las señales abiertas de televisión, la recepción se produce de manera individual o por pequeños grupos (núcleos familiares, fundamentalmente), aunque también es posible organizar las audiencias para la recepción de programas especiales, de acuerdo a intereses específicos. Cada núcleo es anónimo y en el conjunto forman lo que se denomina "masa de audiencia". Por extensión, los medios de comunicación que llegan a miles o millones de personas se les denominan "medios masivos de comunicación". La señal abierta se emite de manera abierta a todo tipo de audiencia, niños, varones y mujeres de toda edad y nivel socio económico. La programación segmenta sus mensajes por tipos de audiencia o por niveles socio-económicos, pero la señal llega a cualquier persona que sintonice un canal.

En el circuito cerrado, la audiencia es muy específica y en alguna medida, reconocible e identificable. La programación se dirige específicamente a esa audiencia. En ese sentido se le denomina "audiencia cautiva".

Es verdad que, con el avance tecnológico, particularmente a partir de la existencia de los satélites de comunicaciones, las diferencias tienden a acortarse en el sentido de las "formas de emisión", porque las señales viajan por el espacio 
a partir de una antena parabólica que lanza los programas a un satélite que los retransmite a otro punto en la tierra donde otra antena las recepciona y distribuye a centros de recepción. Pero sigue siendo un circuito cerrado en la medida que son señales codificadas y se dirigen a públicos específicos. Es el caso, por ejemplo, del Programa de Educación a Distancia del Ministerio de Educación en el 2010 emitió programas educativos por televisión a una red de 180 Centros Educativos Rurales de Educación Secundaria, a través de un satélite. En cada Centro Educativo estaba instalada una antena parabólica y equipos de televisión. Esta señal, la puede recepcionar cualquier persona que tenga una antena parabólica y que tenga la capacidad de orientar la recepción de acuerdo a un código determinado que le permita bajar la señal del satélite. Es por ello que este sistema se considera de circuito cerrado desde la perspectiva de la emisión y la recepción.

La televisión por cable es, en este tiempo, un modelo relativamente nuevo. Sin embargo, su aplicación es tan antigua como la televisión de señal abierta. Todo se sustenta en la idea de la segmentación de las audiencias y en propósitos específicos, canalizando componentes de información, motivación, persuasión y servicio.

Los antecedentes de la televisión por cable se originan en el esquema del circuito cerrado desarrollado particularmente en el campo de la educación. Este esquema operativo ha probado su eficacia al concentrar su atención en las necesidades comunicativas del emisor para una audiencia concreta vinculada a un determinado servicio. No se trata de un público indiscriminado y aleatorio. Es más bien unitario en la función de uso de la información. Las aplicaciones de este modelo son múltiples. Este sistema requiere un pago por suscripción a diferencia de la señal abierta que es de libre disponibilidad.

Entre los sistemas de señales abiertas, por satélite o por cable, lo que define 0 caracteriza una de otra es su función de uso o más propiamente la naturaleza de la audiencia. La primera experiencia probablemente se remonta a lo que la BBC denominó la Universidad Abierta, a finales de los años 40: un sistema de educación universitaria a distancia. Desde entonces se han organizado múltiples experiencias, casi siempre vinculadas a la educación, en casi todos los países. En el Perú, la experiencia del Instituto Nacional de Teleducación (INTE), en los años 70, fue significativa en su intención, pero limitada en su aplicación por factores políticos y terminó en un enorme fracaso burocrático, dos décadas después.

Para el desarrollo del Proyecto que nos ocupa, hemos tomado en cuenta algunos elementos de un canal de televisión abierta y las necesidades puntuales de una audiencia segmentada, característica de los circuitos cerrados, de acuerdo a la naturaleza del servicio que pretende brindar el emisor.

En este sentido, la propuesta de una señal de televisión de circuito cerrado, puede operar con algunos conceptos estratégicos de la televisión de señal abierta: no aburrir al espectador, determinar su tiempo y niveles de atención en relación con el propósito del emisor, dosificación amigable de los mensajes, etc. 
Nuestro Proyecto es en realidad un canal de televisión completo, con algunos elementos de la señal abierta pero circunscritos a la naturaleza de la señal de circuito cerrado. Se trata en todo caso de una propuesta aleatoria.

Un concepto complementario es el del "tiempo muerto". Me refiero a una audiencia que tiene una necesidad específica, pero que debe esperar un tiempo corto para resolver su necesidad de atención. Es ese tiempo de espera lo que puede convertirse en un "tiempo útil" en términos comunicativos. En el Proyecto del Canal BCP, los tiempos de espera se convierten en materia útil. Un minuto o diez de espera, es un tiempo valioso. ¿Por qué no aprovecharlos?.

De esto se trató el Proyecto Canal BCP. Sin embargo, no ha sido tan sencillo lograrlo. Han venido en ayuda a nuestro propósito, las nuevas tecnologías de la información, que nos han permitido consolidar y organizar un servicio de atención al usuario de manera muy articulada. Veamos cómo y por qué.

\subsubsection{La televisión digital y sus aplicaciones}

En los años 90, el desarrollo de los hardware y software disponibles tenían un serio "handicap": no había en los servicios informáticos una capacidad sustentable para archivar imágenes y tenerlas disponibles para su uso. Las memorias de los equipos eran restringidas. La tecnología digital vino en ayuda.

Ahora, todo es posible. Las memorias Ram, la capacidad de comprimir imágenes, sin pérdida de la calidad. Es decir la "digitalización" funcional de información visual y sonora, en tiempo real, se convirtieron en un instrumento operativo que proporcionaba una gran libertad de trabajo. Este considerable avance tecnológico, sumado a los registros electrónicos, abarataron los costos de producción. Registrar en soporte magnético se hizo más caro que el registro digital en soportes de mayor durabilidad. Los equipos de registro de calidad, inundaron el mercado. La "era digital" se puso en marcha. Era el sueño de la "cámara lapicero" elaborada teóricamente por Elie Faure y Germaine Dulac, en la Francia de los años veinte, hecho realidad en el siglo XXI. En aquel entonces señalaban que llegaría un día en que cada persona podría elaborar una película con una cámara tan sencilla como un lapicero. En los años 20 esto era una utopía. Con toda su capacidad visionaria, los teóricos nunca imaginaron una cámara de video instalada en un teléfono celular. Ni mucho menos su capacidad de difusión universal a través de internet.

Desde el punto de vista de la tecnología audiovisual digital, todo es posible. Han desaparecido las complejas "trucas" cinematográficas, las moviolas y las mesas de montaje de tres bandas. Basta una computadora profesional, un monitor y un teclado simple para obtener efectos instantáneos, con sólo pulsar una tecla, lo que antes demoraba tres días, entre la truca y el laboratorio de cine. 
Haber transitado entre las aulas universitarias, la experiencia profesional y la tecnología digital, ha sido una manera de probar los principios esenciales de la comunicación social. Los instrumentos se han transformado, pero los principios esenciales siguen siendo los mismos.

Si el cine, la radio y la televisión fueron los primeros eventos de percepción global, internet y la era digital han acortado la brecha de lo mediático.

En cuanto a la especificidad del Proyecto, es necesario subrayar la complementariedad entre la tecnología, la capacidad comunicativa y la creatividad. Se trata de un sistema que permite articular una gran red sémica, trabajando con signos visuales, sonoros y gráficos para la transmisión de mensajes.

Para lograr esta capacidad expresiva se estudiaron plataformas técnicas (hardware) adecuadas a las necesidades comunicativas planteadas para operar en tiempo real con alta calidad de resolución de las imágenes y sonidos.

Por otro lado se diseñaron programas especiales (software) para el manejo de cada uno de los mensajes, considerando la continuidad del sistema día por día, desde la apertura hasta el cierre del servicio.

El Sistema diseñado permite operaciones por locaciones, es decir sirve tanto al público que asiste al BCP a realizar sus operaciones en ventanilla como a los trabajadores y funcionarios a partir de un mecanismo de información y operaciones asistidas.

El Proyecto se inscribe en un entorno que se podría llamar de "circuito cerrado" si se considera el término que se empleaba para definir un sistema de televisión diseñado para un público específico y cautivo, cuya programación es puntual y usualmente de carácter informativo, educativo o promocional. Por otro lado se encuentra la idea de un canal de televisión de señal abierta, con una programación dirigida a públicos diferenciados, sustentada por la publicidad comercial.

El Proyecto ha tomado de ambas estructuras. Es efectivamente "un circuito cerrado" pero tiene la dimensión de una canal de televisión, con una programación que incluye los servicios informativos para los usuarios, pero también una programación variada de carácter cultural, turístico, de entretenimiento, servicios múltiples e incluso cierta publicidad selectiva, vinculante a las actividades de la empresa, que en este momento ya no es prioridad para el canal BCP.

Para articular la "parrilla de programación" se ha trabajado igual que un canal de señal abierta, es decir desde el diseño de una identidad visual hasta cierto tipo de preferencias de los usuarios para la producción de los programas genéricos. 
Pero el sistema va más allá de lo televisivo. El sistema incorpora base de datos, información puntual para atención del usuario en sus operaciones con la empresa, sobre sus múltiples servicios.

Destaca además como un instrumento para la instrucción y capacitación de sus empleados a partir de una red entrelazada con todas las sedes de la empresa a nivel nacional, una vez concluida la atención a los clientes. Ello ha permitido el desarrollo de lo que hemos denominado "Aula Virtual" interconectada a nivel nacional.

El diseño del Proyecto ha sido exitoso inclusive en su autofinanciamiento, incluyendo el ahorro de tiempo y de gastos. Por otro lado, la tecnología de última generación, incorporada al sistema, ha significado también economía en los procesos operativos, economía de tiempo y de personal técnico.

Mediante un contrato de servicios que implica exclusividad, la producción de los programas en video, que se renuevan cada mes, es encargada a la empresa que diseñó y ejecuta en la actualidad el sistema del "Canal BCP".

El modelo de este sistema, con sus componentes de hardware y software especializados, además del soporte de producción de programas en video, servirá a otros sistemas operativos como el que a lo largo del tiempo y la experiencia profesional significa este Proyecto.

\subsubsection{Diseño de Proyecto}

Todo proyecto comunicativo parte de una metodología operativa que permita la planificación y manejo del proyecto. Para establecer el Marco Lógico, es decir la identificación de las necesidades específicas, los objetivos operacionales y los resultados que esperan obtenerse. A partir de este esquema se pueden desarrollar todas las actividades del Proyecto, planificando los tiempos, estableciendo los controles de calidad necesarios y luego monitorear los resultados.

Las etapas para el diseño del Proyecto fueron las siguientes:

a) Análisis de Necesidades

b) Estudio de Audiencia (Determinación de Públicos Objetivos)

c) Diseño de la Identidad Visual para el Canal BCP y Diseño de la Programación

d) Diseño del Sistema (Upgrade a Dvx, desde Avid CinePack)

e) Sistema Técnico (Hardware)

f) Sistema Operativo (Software) 
Describiremos cada una de estas etapas que formaron parte del Modelo Metodológico empleado en el Diseño del Proyecto.

\subsubsection{Análisis de Necesidades}

En toda estrategia de trabajo comunicacional, es necesario establecer un correlato entre lo que se tiene $(A)$ y lo que se quiere tener $(B)$.

Es un cuadro comparativo por variables para ubicar las discrepancias entre A y B. Los resultados de los análisis son recomendaciones operativas para la gestión y la producción del Canal BCP.

En este caso, las variables son las siguientes:

- Naturaleza del medio

- Características de la audiencia

- Propósitos del emisor

Cuando se habla de naturaleza del medio, nos referimos a los tipos de soporte que se van a emplear. Si es sólo un medio audiovisual o tiene también un soporte complementario, impreso, por ejemplo. Aquí se deben señalar las recomendaciones para la emisión técnica de los mensajes.

El análisis del tipo de audiencia es esencial en la medida que se tienen en cuenta el interés general de la audiencia objetivo, su nivel socio-económico, nivel educativo, disponibilidad de tiempo para recibir mensajes, grado de receptividad y credibilidad.

Los propósitos del emisor deben estar claramente determinados para que sean correspondientes con los cuadros de análisis de necesidades.

\subsubsection{Naturaleza del medio}

Se parte de que el medio es un soporte de naturaleza audiovisual que emite señales de televisión por circuito cerrado. No se trata sólo de un deseo a ser satisfecho. Es necesario considerar algunas potencialidades y limitaciones generales del medio audiovisual y por ende del Canal BCP

\subsubsection{Potencialidades}

- El medio audiovisual tiene una enorme aceptación y alta credibilidad. Este hecho posibilita inferir mecanismos subliminales de persuasión en la configuración de los mensajes.

- El Canal BCP es un canal de televisión por circuito cerrado, segmentado por tipo de audiencia y más específicamente por el tiempo de recepción, lo que permite focalizar los mensajes. 
- La modalidad de recepción permite aprovechar el "tiempo muerto" de la audiencia en un "tiempo informativo y comunicativo".

- La información se refiere a los datos, conocimientos y sugerencias para la comprensión y apreciación acerca de los servicios que brinda el Banco de Crédito del Perú, en términos de oportunidad y calidad..

- La comunicación tiene un doble propósito. Por un lado sensibilizar y motivar a la audiencia y por otro lado marcar puntos de interés social, educativo, cultural y de entretenimiento.

\subsubsection{Limitaciones}

Los medios de comunicación masiva sonoros y audiovisuales tienen en su propia naturaleza las siguientes desventajas:

- Fugacidad de los mensajes

- Tiempo limitado para la fijación de los mensajes

- Interferencias o "ruidos" comunicacionales que restringen la atención de la audiencia sobre los mensajes.

Para la estrategia operativa, en este acápite, se recomienda actuar sobre las limitaciones, aprovechando las potencialidades del medio.

El siguiente momento se refiere a las recomendaciones o prescripciones de producción a partir del análisis de necesidades y la naturaleza del medio. En el caso del Canal BCP, las prescripciones de producción fueron las siguientes y aún siguen en la base de la programación:

a) Elaborar los mensajes de manera concisa y clara.

b) Privilegiar la autosuficiencia de los mensajes visuales sobre los mensajes verbales. Sólo incluir mensajes verbales cuando las imágenes no sean explicitas y no puedan explicarse por sí mismas. No olvidemos que la audiencia tiene la capacidad de decodificar imágenes y sonidos no verbales, por su propia experiencia audiovisual (pertinencia televisiva)

c) Trabajar, creativamente, los elementos visuales gráficos (3D, dinámica gráfica, estandarización icónica del $\mathrm{BCP}$, etc.) para encapsular los mensajes.

d) De ser posible, complementar los mensajes con medios impresos, (folletos, trípticos, láminas, dossier, etc) para resolver el problema de la fugacidad, aún cuando puedan parecer reiterativos. 


\subsubsection{Características de la audiencia}

El Canal BCP tiene dos tipos de audiencia. Por un lado son los usuarios de los servicios del Banco en las ventanillas y oficinas de sus agencias. Por otro lado, son los funcionarios y empleados del propio Banco. En el caso de los empleados y funcionarios del Banco, el Canal BCP configura una línea especial de programación, que llamaremos "aula virtual", mediante la cual se desarrollan programas de capacitación a distancia. La red informática que enlaza a todas las agencias del país, permite operar cursos desde la matriz de Lima, con el consiguiente ahorro de tiempo y estandarización de los servicios en cuanto a calidad y oportunidad, incluyendo feedback virtuales a cuestionarios preparados para evaluación.

La audiencia en ventanilla se estima en 250 mil espectadores por día y a nivel nacional. Esta es la audiencia objetivo del Canal BCP.

Aquí cabe señalar la expansión del Banco de Crédito en cuanto sus servicios y productos, teniendo en cuenta la bancarización desarrollada en la última década. El sistema financiero peruano ha sufrido algunas crisis como la desaparición de algunos bancos y lo ocurrido con CLAE en esos años. Estos hechos marcaron una brecha en la credibilidad en el sistema financiero, base para el desarrollo del sector. En ese sentido el BCP ha demostrado su solidez y una credibilidad constante.

Por otro lado, la actividad económica informal ha permitido desarrollar procesos muy interesantes como es el caso del emporio comercial de Gamarra. A pesar de la conformación inicial de empresas individuales o familiares, probablemente no registradas, este sector ha inyectado a la economía real una liquidez considerable, que ha pasado necesariamente por el sistema financiero formal. EL BCP no ha sido extraño a este flujo de clientes.

Veamos algunos datos significativos de este proceso de expansión del sistema financiero.

Cuadro Comparativo de expansión de Oficinas del BCP a nivel nacional de los últimos 10 años.

\begin{tabular}{|l|c|c|c|c|c|}
\hline \multicolumn{1}{|c|}{ Año } & $\mathbf{2 0 0 9}$ & $\mathbf{2 0 1 0}$ & $\mathbf{2 0 1 1}$ & $\mathbf{2 0 1 2}$ & $\mathbf{2 0 1 9}$ \\
\hline $\begin{array}{l}\mathbf{N}^{\circ} \text { de } \\
\text { Agencias }\end{array}$ & 316 & 320 & 328 & 337 & 459 \\
\hline $\begin{array}{l}\mathbf{N}^{\circ} \text { de } \\
\text { cajeros } \\
\text { automáticos }\end{array}$ & 468 & 500 & 550 & 655 & 2311 \\
\hline $\begin{array}{l}\mathbf{N}^{\circ} \text { de } \\
\text { agentes } \\
\text { BCP }\end{array}$ & 0 & 0 & 61 & 551 & 5573 \\
\hline
\end{tabular}


Estos datos implican un universo muy importante en términos de audiencia objetivo. Para el proyecto este proceso de expansión del BCP implicaba una percepción de la audiencia que exigía necesariamente nuevas perspectivas comunicacionales. Pero aparte de los productos y servicios financieros del BCP, también se expandía sus servicios sociales y de proyección cultural, vinculados a la educación, la cultura y el deporte. El canal BCP debía ir abriendo su pantalla a toda esta gama creciente de temas desde el punto de vista de la difusión.

\subsubsection{Servicios sociales del BCP}

- Semilleros deportivos

- Museo

- Publicaciones

- Obras sociales

- Apoyo a la educación,

- Piloto 20

- Aula Empresa

- Matemáticas para todos

- 20 en Mate.

A partir de estos datos, el tratamiento informativo del Canal BCP se amplió considerablemente teniendo en cuenta ya no una audiencia estandarizada y uniformizada sino una audiencia vinculada al BCP por diversas áreas de interés.

Si se define una audiencia por su condición socio económica $(A, B, C, D, E)$, los usuarios que acuden a ventanilla son, en su mayor parte, Empleados, profesionales, amas de casa, trabajadores independientes, comerciantes informales, etc.

Teniendo en cuenta que el principal interés de la audiencia es la de realizar un trámite específico, hay un tiempo de espera que varía entre los 1 y 60 minutos. La estructura de programación tiene en cuenta todos estos datos.

Este es el tiempo que tiene Canal BCP para capturar la atención de la audiencia respecto a su programación. Este hecho marca la necesidad de elaborar microprogramas cuya duración no sea mayor de 2 minutos y esta es la principal prescripción de producción atendiendo al carácter de la audiencia, sin dejar de ser entretenido y claro en los mensajes que se emiten.

Por otro lado, para impulsar todo este proceso se requería nuevos enfoques publicitarios como el "Below The Line".

Según la definición, el BTL resulta incongruente con relación a la televisión de señal abierta, pero resulta altamente compatible con un canal de circuito cerrado como el Canal BCP. 
En la experiencia nuestra, buena parte de la facturación por servicios publicitarios se encuentra sustentada en la orientación del BTL como concepto estratégico. El porcentaje de facturación restante se produce por servicios publicitarios con el enfoque tradicional, es decir para la televisión de señal abierta.

El canal BCP nos ha permitido desarrollar conceptos creativos, dirigidos a mostrar nuevas formas de acercar al público a la comunicación integral que no es sólo publicitaria. Los resultados son muy satisfactorios.

\subsubsection{Propósitos del emisor}

Se han señalado dos propósitos generales desde el punto de vista del emisor:

a) Brindar información sobre el propio Banco, sus servicios y productos, el rol de ayuda social, el carácter de promotor empresarial y otras actividades relacionadas específicamente con las funciones del Banco.

b) Comunicar mensajes motivadores de carácter social, educativo, cultural y de entretenimiento

c) Comunicar mensajes publicitarios sobre servicios y productos, mensajes de ayuda social de otras empresas o instituciones

Estos propósitos que aparecen condensados en los enunciados son mucho más complejos en la medida que el proceso de bancarización ha crecido considerablemente en los últimos años. A medida que la estructura económica del país ha permitido un perfil más sólido de las cifras macroecómicas, también se ha ampliado el consumo. En el sistema financiero, la confianza en la estabilidad económica genera más confianza. Basta observar el crecimiento sostenido de las tasas de rentabilidad del sistema en los últimos 5 años. El BCP no ha sido ajeno a este proceso. Liderar el Mercado financiero ha implicado ofrecer nuevos productos y nuevos servicios. Aquí un cuadro básico en el que se puede explicar la enorme variedad de productos que el BCP ofrece a sus clientes. No es la totalidad de los productos en cartera del BCP. No es este el espacio para detallar cada uno de ellos. Sólo queremos testimoniar la complejidad del sistema informativo que el Canal debe procesar diariamente desde la perspectiva de la producción audiovisual.

\subsubsection{Información de productos}

\author{
- Cuenta de ahorros y corriente \\ Cuenta Cero BCP \\ Cuenta Libre BCP \\ Cuenta corriente \\ CTS \\ Cuenta a plazo
}

\section{Seguros}

Seguro Vida Retorno

Seguro múltiple

Seguro accidentes retorno

Seguro Protección de Tarjetas de

Crédito 
> Certificado Bancario Moneda

Extranjera

> Antiguas Cuentas de Ahorro

- Tarjetas de crédito y débito

Tarjeta de Crédito Visa Clásica

Tarjeta de Crédito Visa Oro

Tarjeta de Crédito Visa Platinum

Tarjeta de Crédito Visa LANPASS

Clásica

> Tarjeta de Crédito Visa LANPASS Oro

Tarjeta de Crédito Visa LANPASS

Platinum

> Tarjeta de Crédito Visa PRIMAX

Clásica

> Tarjeta de Crédito Visa PRIMAX Oro

Tarjeta de Crédito Visa Plaza San

Miguel

American Express Clásica

American Express Green

American Express Gold

American Express Platinum

American Express LANPASS Gold

Credimás

Créditos Personales

Crédito en Efectivo

Crédito Vehicular

Créditos para Estudios

Créditos Hipotecarios

Crédito Hipotecario

Crédito Mivivienda

Crédito Mivivienda (antiguo)

Crédito Mivivienda con Remesas

(antiguo)

Crédito Hipotecario con Remesas

Crédito Hipotecario con Ahorro Local

Crédito Hipotecario para Ampliación

de Vivienda

Crédito Proyecto MiHogar
SOAT

Seguro Oncológico

Seguro de Desempleo e Incapacidad

temporal por enfermedad o accidente

\section{Envíos y transferencias de dinero}

Transferencias al extranjero

Transferencias del extranjero

Envíos de dinero a Perú (Remesas)

Giros Nacionales

Transferencias Interbancarias

\section{Inversiones}

Fondos Mutuos

Agente de Bolsa

Certificado Bancario

Inversiones en línea

Asesoría de Inversión

Mercado al día

\section{Servicios diversos}

Cheques de gerencia

Cheques de viajero

Custodia de valores

Fideicomiso

Cajas de seguridad

Cambios de moneda

Tarjetas pre pago virtuales

Cobranzas de cheques del exterior

Débito Automático

Cada uno de estos productos, implica la necesidad de su difusión. El Canal BCP es, en esta medida, el medio de difusión sostenido para atender, explicar y promocionar el complejo sistema de oferta de productos bancarios y financieros del $\mathrm{BCP}$, independientemente del uso de otros medios o formas de difusión.

La información es uno de los insumos de los mensajes que el Canal BCP tiene que preparar cada mes. El Diseño del Sistema permite cumplir con este propósito esencial, sin ser el único. 
Por otro lado, los servicios de promoción cultural, educativa y de carácter social del BCP han producido beneficios y reconocimiento en diversos sectores. Podemos mencionar como ejemplos, el programa de semilleros deportivos, atletismo, voley, fútbol, El Programa de impulso y complementación al razonamiento matemático para Centros Educativos Nacionales (Piloto 20, Página Webb 20 en Mate), el Programa del Voluntariado Institucional, Aula Empresa, el Programa de Becarios, etc.

Todos estos productos y servicios han alimentado el diseño y la identidad del Canal BCP y su proyección como un servicio adicional a los muchos que brinda el BCP; ingresando también aquellos que conforman el Grupo Crédito como Pacífico Cia. de Seguros, Prima AFP y Credicorp.

\subsubsection{Diseño de identidad para el Canal BCP}

Todo canal de televisión requiere de una serie de elementos visuales y sonoros que identifiquen su señal. Es el equivalente de una marca en la publicidad de un producto.

Para el diseño de la identidad visual del Canal BCP se tuvo en cuenta sus isotipos y sus propias marcas, en la medida que el canal configura un servicio más del Banco.

En los gráficos y elementos visuales se ha privilegiado los colores azules, naranjas y blancos que identifican los isotipos del Banco. Estos elementos se utilizan en la apertura y cierre de cada programación y en la división de los bloques o microprogramas.

\subsubsection{Descripción del Sistema}

El Complejo del Canal BCP emplea el sistema BMatic, que es un instrumento de gestión de oficinas, que además de administrar las colas de atención, permite medir localmente la situación operativa funcional de una oficina, obteniendo una valiosa información estadística de la afluencia de público, perfiles, horas y días picos, productividad de los operadores de atención, deserción de clientes frente a la espera para ser atendidos, etc.

Ha sido desarrollado en un esquema cliente/servidor en una plataforma de redes Windows con base de datos Access o MSDE. Provee información en línea de la operatividad de una agencia u oficina, como clientes que estén atendiendo, clientes en espera, tiempos de atención, tiempos de espera, etc.

Desde cualquier punto de red de la oficina se puede obtener la información en tiempo real. 
Es paramétrico, permitiendo el uso de diferentes tipos de tickets (sin límite), un número ilimitado de Ticketeras así como de Televisores. Los televisores muestran los tickets y la estación donde será atendido, el televisor posee la ventaja de mostrar videos a la vez que muestra los números de los tickets, estos videos deben ser de información para el cliente, como nuevos servicios, cambios, mejoras, noticias, propaganda, promociones, videos culturales, etc.

De acuerdo a la política de la Institución; también (opcionalmente) permite mostrar una línea de mensajes que se desplaza en forma de marquesina o banner, cuyo contenido también es configurable. Es posible tener televisores en cascadas (varios televisores conectados en serie mostrando la misma señal de video).

Permite priorizar la atención de los clientes de la Institución de acuerdo a las directivas que se determine, soportando tres tipos de asignación de tickets que son:

- Secuencial: Se atiende un ticket de la lista de tipos de tickets asignados para la estación de acuerdo al orden de llegada.

- Prioridades: A cada tipo de ticket asignado a la estación se le da una prioridad. Aquí siempre se busca primero el ticket de la más alta prioridad, si no se encuentra se busca el de la siguiente y así sucesivamente.

- Ratios: A cada tipo de ticket asignado a la estación se le da una prioridad y un ratio (cantidad de tickets a atender antes de pasar a la siguiente prioridad). Así, el sistema buscará asignar los tickets de mas alta prioridad para la estación hasta completar el ratio respectivo, si no se encuentra se busca el de la siguiente prioridad y se trata de completar su ratio y así sucesivamente.

Esta priorización se define por cada ventanilla o puesto de atención soportando una combinación de estos tipos de asignación de tickets dentro de la oficina.

En resumen el producto BMatic Lite es un sistema computacional, que integrado a los aplicativos de ventanilla y/o plataforma de la Institución permite:

- Mejorar substantivamente la atención a los usuarios

- Optimizar el uso de los recursos físicos y humanos en las oficinas.

- Entregar información detallada de la base de datos para el análisis operativo de las oficinas.

- Entregar estadísticas de atención de la oficina por diferentes conceptos (tipos de clientes, oficinas, estacionalidad por horas, días de atención, etc.) 
- Establecer un centro de control local, que permita conocer y supervisar la operatividad de la oficina en tiempo real.

Todo este sistema funciona en base a un soporte técnico (hardware) y operativo (Software) altamente especializado que se describe a continuación.

\subsubsection{Sistema Técnico: Hardware}

El sistema del Canal BCP incorpora equipos de última generación que permite su uso en tiempo real y forman una unidad funcional desde la sala de espera de los clientes hasta la conectividad y la producción de la parrilla de programación que se renueva cada mes.

Los Componentes Tecnológicos del Sistema son los siguientes:

- Dispensador de Tickets (Ticketera)

- Interfase PC-TV

- Televisores

- Amplificar y/o distribuidor de video

- PC servidora y controladora de video

- Sonido Tubular diseñado especialmente para envolver al espectador.

La descripción del Hardware da una idea del Complejo y su funcionalidad.

Buscar los componentes, determinar su funcionalidad a las necesidades del Diseño del Canal BCP fue una tarea muy puntual y técnica. He aquí la descripción de los componentes del Hardware:

\section{a) Dispensador de Tickets (Ticketera)}

Sirve para dispensar los tickets de atención a los clientes, es una microcomputadora conectada como una PC más a la red de la institución.

\section{b) Modelo BM02}

El terminal tiene los siguientes componentes: 
- 01 Case, incluyendo sistema de cerradura y bisagras, personalizado a los colores que el cliente defina ( 2 colores).

- Terminal Verifone Línea OMN, totalmente programable sus distintos componentes (en lenguaje $\mathrm{C}$ ). Cuenta con batería para conservar el programa y archivos ante falla de fluido eléctrico, la duración de la batería es de 5 años. Este terminal inclúyelos siguientes componentes:

- 01 Visor de pantalla gráfica de 4 líneas por 25 columnas. Puede usarse como 2 líneas por 18 columnas de mayor tamaño de carácter o 3 líneas. Permite formatos de imágenes, logos, caracteres especiales y digitos.

- 01 lector de banda magnética bidereccional pista 1 y 2, tipo swiping.

- 01 Teclado ampliado que incluye 8 teclas de función y 16 alfanuméricas.

- 01 impresora de rollo, térmica Epson de alta velocidad, $14-26$ lps, 42-56 caracteres por línea, sensor de fin de papel reconocible por programa. Incluye cortador de papel automático. Permite la impresión de gráficos y código de barras.

- 01 Porta rollo de papel.

- 01 fuente de poder.

- Cables y accesorios correspondientes.

- Parante de metal o totem para su instalación en la oficina.

\section{c) Televisores}

Los televisores son ubicados en lugares de alta visibilidad para los clientes. Están conectados a una microcomputadora dedicada que los controla y sirven para informar a los usuarios en la ventanilla que van a ser atendidos.

Se pueden conectar varios televisores en cascadas o serie, mostrando la misma información.

\section{d) Interfase PC-TV}

Es un equipo que permite que las imágenes provenientes de una PC puedan ser observadas en un Televisor. 


\section{e) Amplificador $y / 0$ distribuidor de video}

Son dispositivos que permiten reproducir la misma señal de video en varios televisores. Pueden ser pasivos (Spliter) como activos. Los pasivos permiten conectar varios televisores mostrando la misma señal. Los activos adicionalmente a la distribución de la señal de video, también la amplifican permitiendo llevarla a una cantidad mayor de Televisores. Son usados cuando se necesitan llevar la misma señal a más de dos televisores.

La ingeniería de sonido digital está incorporada también al sistema de distribución.

\section{f) PC Servidora y controladora de videos}

La configuración de esta unidad es la siguiente:

- Pentium IV con procesador Intel de $2 \mathrm{Ghz}$

- 512 MB de memoria RAM

- Disco duro de $20 \mathrm{~GB}$

- Tarjeta de red 3 Com DE 10/100 Mbs

- Tarjeta de Video de $31 \mathrm{MB}$

- Tarjeta de Audio Sound Blaster Modelo Value Live

- CD drive de 52X

- Monitor, teclado y mouse

- Windows 2000 Profesional con service parck 2

\section{g) Sistema Operativo (Software)}

No es un solo sistema operativo. Son varios módulos, con funciones distintas, pero integrados para su operatividad en tiempo real. Los Módulos y sus funciones son los siguientes:

- Módulo de definiciones de agencia y parámetros de atención (Mantenimiento).

- Módulo de generación de Tickets, por Tipo de Operación o Cliente (Generador para la Ticketera)

- Componentes en el Servidor para atender los requerimientos de los módulos clientes del Sistema 
- Interfase con aplicativo de Ventanilla de la Institución, para la solicitud de Tickets a atender (Ventanilla)

- Módulo del televisor (Display)

- Módulo de consultas y reportes estadísticos (Reportes)

- Módulo de administración de acceso a los módulos (Seguridad)

Este es el complejo técnico y operativo del Sistema que emplea el Canal BCP para la configuración del circuito cerrado. En un canal de señal abierta, todo este sistema sería reemplazado por los transmisores, controles de video y audio y por la operatividad del tráfico de señales al aire.

\subsubsection{La Programación}

Un canal de televisión tiene una unidad técnica, una unidad de programación y una unidad de producción

La unidad de programación realiza los estudios de audiencia que determinen preferencias por estratos socio económicos, horarios, tipos de programas. El feedback que obtiene es el "rating" o indicador de sintonía de su programación.

En el caso del Canal BCP, también se tiene en cuenta la audiencia, pero considerando fundamentalmente, los tiempos de recepción y la función del sistema. Es una audiencia cautiva a diferencia de un canal de televisión de señal abierta.

\subsubsection{La recepción: consideraciones básicas}

El sistema comienza a funcionar apenas el usuario entra a una oficina o agencia del Banco a realizar sus operaciones. Se encuentra con una ticketera en la cual debe obtener un código que marca el momento en que será atendido. Luego pasa a la sala de espera, siguiendo una guía o señales de circulación (señalética). La sala de espera es en ese momento, la sala de recepción del Canal BCP. EI usuario está atento al televisor porque ahí debe aparecer su código de atención. Los televisores están ubicados a una altura cómoda y visible. El sistema de sonido está estandarizado y tiene una ubicación envolvente con volumen calibrado de acuerdo al tamaño del local. Incluye también un timbre "din-don" para llamar la atención.

El promedio de tiempo de espera de un usuario puede llevarle entre 1 y 60 minutos, dependiendo de la prioridad que el sistema señale para ser atendido. Este es el tiempo que la programación tiene en cuenta para capturar la atención del usuario y emitir los mensajes. 
La parrilla de programación se estructura en un reel de 60 minutos que se repite automáticamente en loop hasta el cierre de la oficina. Los tipos de programas se emiten aleatoriamente y son de 3 tipos o líneas diferenciados: La parrilla de programación se cambia cada mes, con nuevos programas.

a) Microprogramas, spots, mensajes puntuales de carácter informativo, acerca de los servicios y productos que ofrece el Banco a sus clientes.

b) Microprogramas de carácter social, cultural, educativo y de entretenimiento.

c) Spots publicitarios de servicios $y / 0$ instituciones

El porcentaje mayor de la programación lo ocupan los microprogramas del tipo b).

Esta caracterización permite constituir líneas de producción para alimentar la programación.

Cabe señalar que debido a la mayor oferta de productos y servicios del Banco, la línea de programación referida a publicidad de terceros ha sido suspendida.

Algunas de las líneas temáticas comunicativas son las siguientes:

a) Cultura (p.e :Testimonios de escritores, pintores, artistas, historiadores, etc.)

b) Educación (p.e. Promoción de la lectura, atención primaria de la salud, protección del medio ambiente. Prevención de desastres naturales, etc.)

c) Rutas y atractivos turísticos del Perú (Todos los circuitos en costa, sierra y selva, arte popular, gastronomía, etc.)

d) Entretenimiento (Video clips musicales, humor, notas de actualidad, conciertos de música, notas de obras de teatro, pintura, escultura, arquitectura, bloopers de deportes, etc.)

Hasta la fecha se tiene registrado un total de 2000 horas en matrices digitales, que constituyen un importante archivo y a la vez un banco de imágenes y sonidos que permitirán diversas formas de expansión o nuevos productos audiovisuales. Cada nuevo producto o servicio que el BCP lanza a difusión, se incorpora a través de su sistema intranet a cada terminal de computadora, de manera que los funcionarios y trabajadores a nivel nacional cuenten con una ayuda directa para ampliar y potenciar la promoción y fuerza de venta del producto. 
(Ver anexo: DVD conteniendo un reel de la parrilla de programación reciente del Canal BCP)

\subsubsection{Aula Virtual}

El Canal BCP usa su sistema para el desarrollo de cursos de instrucción y capacitación a su personal. Son aulas virtuales que operan fuera de los horarios de atención al público y permiten un considerable ahorro de tiempo y dinero en la medida que se trata de la modalidad de educación a distancia.

Aún no se han desarrollado otras perspectivas vinculadas al aula virtual, como cursos de extensión académica, cultural o video conferencias, por ejemplo. Pero las posibilidades de expansión son prometedoras y el BCP tiene entre sus proyectos de desarrollo inmediato la constitución de una videoteca que permitirá un mayor flujo de usuarios dentro y fuera del propio Banco. Evidentemente, la videoteca BCP constituirá una nueva forma de creación y de expansión de servicios, vinculada al Canal BCP.

\subsubsection{La Producción}

Como todo canal de televisión, es necesario planificar, organizar y desarrollar la producción de los microprogramas. Este proceso incluye desde el acuerdo de producción con los funcionarios del Banco, guiones, registro, post-producción, hasta la entrega del reel completo. Los tiempos de producción son muy ajustados, pero sin dejar la creatividad y la calidad en su presentación.

La operación del Canal BCP corresponde al propio Banco, pero la producción y realización de los programas la productora, mediante un contrato para tal efecto.

El "timing" de producción, en la experiencia, también ha sido ajustado en términos de productividad. Las etapas de trabajo y los tiempos correspondientes son los siguientes:

- Acuerdo de producción (1 día)

- Guiones (2 días) y Creatividad

- Estructura de la programación y planificación de la producción (1 día)

- Registro de imágenes y sonidos (Promedio de tres días, salvo que las locaciones y programas requieran viajes fuera de Lima)

- Pauteo y edición off line ( 2 días)

- Aprobación, por parte del Canal BCP, de la parrilla de programación del mes (1 día)

- Aprobada la programación se procede a la post.producción (edición gráfica, musicalización, locución profesional, efectos y logo en gráfica 3D, títulos) en sistema AVID digital, donde se masteriza y digitaliza (2 días)

- Coordinación final y aspectos administrativos 
- Multicopiado (1 día)

- Entrega del producto final en extensión Dvx y discos compactos de video para PC.

Este proceso se repite mes a mes y requiere de una atención especial en el funcionamiento de las productoras.

\subsubsection{Conclusiones}

a) El funcionamiento del Canal BCP es una experiencia exitosa en todo sentido, incluyendo no sólo el autofinanciamiento de la producción a partir de la publicidad, sino que el ahorro de tiempo en la atención al público se refleja en una mayor productividad y también los gastos en programas de capacitación se han reducido considerablemente, permitiendo al Banco márgenes de utilidad y eficacia significativos.

b) Las nuevas tecnologías digitales han permitido acelerar los procesos de producción y realización por un lado y obtener resultados más rápidos y de mejor calidad en la distribución y emisión de la programación.

c) El Modelo Operativo del Canal BCP, ha servido para brindar este servicio a otras empresas e instituciones a nivel nacional e internacional.

\subsubsection{Descripción del caso}

Este sistema ordenó la atención al cliente y logró un acercamiento amical entre Cliente y Banco. Además de promocionar sus productos a los clientes del Banco brindándoles entretenimiento y cultura, también con este cctv se capacitó al personal del banco.

\subsubsection{Resultados obtenidos}

Se logro vender y lanzar nuevos productos a través del Canal Bcp, por ejemplo crédito automotriz, crédito inmobiliario o envíos de dinero, posiblemente se dobló las ventas en estos y muchos otros productos del Banco, las estadísticas a la fecha son muy confidenciales pero el hecho de que todos los meses se hacia nuevos videos y lanzamientos de nuevos productos por el cctv nos indicaba que el Banco estaba contento con los logros y las ventas, la información la manejaban ellos muy celosamente, nosotros éramos los 
proveedores de contenidos tras el breef informativo que el área encargada enviaba de cada producto

\subsubsection{Materiales producidos}

Se produjeron gran cantidad de contenidos de entretenimiento, cultura, deporte y temas del Banco como campañas, videos institucionales del Grupo Bcp- Pacifico - Prima y Grupo Romero lográndose una programación de 45 minutos mensuales.

Se adjunta link de videos para su descarga

Link de Videos:

video canal bcp 01:

https://visionariatv.com/webtv/index.php/video/101/canal-bcp-01/

video anunciantes:

https://visionariatv.com/webtv/index.php/video/100/anunciantes/

video canal bcp 02:

https://visionariatv.com/webtv/index.php/video/99/canal-bcp-02/ 


\subsection{PROYECTO CANAL WEB HD}

\subsubsection{Objetivos de Canal WEB HD}

\section{Objetivo general}

- Actualizar la Televisión de señal abierta y la televisión de los circuitos cerrado CCTV mediante otros mecanismos de comunicación

\section{Objetivos específicos}

- Con la finalidad de estar a la vanguardia tecnológica, se desarrolló esta Plataforma web, que permite ver en tiempo real, cualquier evento y acción en tiempo real, lo que le llamamos Transmisión en vivo, Publicar los videos on demand, fotos, entre otros y compartirlas en cualquiera de las redes sociales que actualmente se tiene en el momento que desee.

\subsubsection{Descripción del caso}

- El canal web HD es una plataforma que permite transmitir en vivo todos los eventos y mensajes que desees realizar, programar videos generando una parrilla de programación los mismos que puede ser vistos desde cualquier pc, celular y/o Tablet de última generación con internet, puesto a tu disposición de manera inmediata.

- El Canal Web HD proporcionar un servicio de difusión de contenidos audiovisuales por internet, el mismo que puede ser accedido a través de múltiples plataformas (PCs, smartphones y tablets) e integrado a redes sociales.

\subsubsection{Características}

- Configuración de plataforma en un servidor streaming dedicado solo para el servicio.

- Servidor Cloud.

- Diseño corporativo.

- Escalamiento de concurrencia según necesidades.

- Seguridad SSL y/o Firewall según requerimiento.

- Almacenamiento de videos. 
- Permite almacenar en la nube contenido para difundir y compartir información actualizada empresarial a sus suscriptores mediante tecnologías de streaming de video.

- Transmisión de conferencias: permite realizar streaming en tiempo real.

\subsubsection{Beneficios:}

- Ubicuo: los usuarios pueden conectarse desde cualquier lugar con Wifi y sin costo.

- Útil: Emite información de utilidad para el público

- Visual: Utiliza contenidos multimedia con alto impacto visual

- Social: Comparte contenidos y publicaciones sobre redes sociales

- Múltiples plataformas: Permite acceso desde cualquier dispositivo: PC, notebook, Smartphone o tablet.

- Simple: Solo requiere una conexión a internet mínima de 4 Mbps para subir el contenido a la plataforma Cloud del servicio.

- Seguro: Información alojada sobre plataformas confiables y supervisadas 24/7.

- Canal web HD, ha sido diseñado para ser compatible con la mayoría de navegadores Web que soportan Hmtl5 o Flash Player, tanto para PC como smartphones y tablets. Ha sido probado en Internet Explorer 7, 8, 9, Chrome, Safari, Firefox, Opera, Dolphin, etc.

\subsubsection{Implementación del Canal Web - Esquema de Gantt}

\begin{tabular}{|c|c|c|c|c|c|c|c|c|c|c|c|c|}
\hline & & & & \multicolumn{9}{|c|}{ DÍAS } \\
\hline & TAREA & ACCIÓN & RESPONSABLE & 1 & 2 & 3 & 4 & 5 & 6 & 7 & 8 & 9 \\
\hline & & Entrega de orden de servicio y/o Aprobación de Propuesta & Cliente & & & (a) & 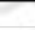 & & & & & \\
\hline & & Reunión coordinación & Cliente + Visionaria & & & & 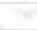 & & & & & \\
\hline \multirow{8}{*}{1} & \multirow{8}{*}{$\begin{array}{c}\text { Implementación de } \\
\text { Canal Web Fase I }\end{array}$} & Entrega de Dominio y Hosting para implementar el CanalWeb & Cliente & & B. & & 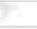 & & & & & \\
\hline & & Activación y Configuración del canal & Visionaria & & & 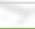 & & & & & & \\
\hline & & Selección y Digitalización de videos para publicación en canal & Visionaria & & & & & & & & & \\
\hline & & Implementación de Canal Web y publicación & Visionaria & & 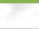 & & & & & & & \\
\hline & & Revisión de Diseño y pruebas para transmisión en vivo & Visionaria & & & & & & & & & \\
\hline & & Envio de señal & Visionaria & & & & & & & & & \\
\hline & & Pruebas y Revisiones & Cliente & & & & & & & & & \\
\hline & & Aprobación Final & Cliente & & & & & & & & & \\
\hline \multirow{6}{*}{2} & \multirow{6}{*}{$\begin{array}{l}\text { Implementación de } \\
\text { Canal Web Fase II }\end{array}$} & Capacitación a personal & Visionaria & & & & & & & & & \\
\hline & & Capacitación Web & Visionaria & & & & & & & & & \\
\hline & & Capacitación Digitalización de videos & Visionaria & & & & & & & & & \\
\hline & & Capacitación transmisiones en Vivo & Visionaria & & & & & & & & & \\
\hline & & Capacitación técnica de equipos de transmisión & Visionaria & & & & & & & & & \\
\hline & & Coordinación y asesorias permanentes & Visionaria & & & & & & & & & \\
\hline
\end{tabular}




\subsubsection{Equipamiento Técnico para un Estudio de Tv Web}

\begin{tabular}{|c|c|l|}
\hline ITEM & CANTIDAD & \multicolumn{1}{c|}{ DESCRIPCIÓN } \\
\hline & 01 & PC CON PROCESADOR DE ULTIMA GENERACIÓN PARA TRANSMISIÓN WEB \\
\hline & 01 & MONITORES LED HD 32" \\
\hline & 02 & CÁMARAS PARA ESTUDIO FULL HD CON TRIPODE \\
\hline & 02 & CÁMARAS PARA EXTERIORES FULL HD CON TRIPODE \\
\hline & 01 & SWITCHER DE 4 CANALES \\
\hline & 01 & PC DE TITULOS Y GRÁFICAS \\
\hline & 01 & UNA GRABADORA HD DIGITAL \\
\hline & 01 & REPRODUCTOR DE TARJETAS \\
\hline & 08 & TARJETAS PARA CÁMARAS Y GRABAR PROGRAMAS \\
\hline & 02 & CONSOLA DE AUDIO DE 8 CANALES PARA ESTUDIO Y PARA EXTERIORES \\
\hline & 04 & MICROFONOS PECHEROS \\
\hline & 01 & CAÑA PARA AUDIO \\
\hline & 02 & MICROFONOS DE MANO \\
\hline & 02 & PEDESTAL DE MESA \\
\hline & 08 & KIT DE LUCES CON TRIPODE LED \\
\hline & 01 & MODEM CABLEMAGICO \\
\hline & 04 & MONITORES 32" PARA SWITCHER \\
\hline & 01 & PC ULTIMA GENERACIÓN PARA DIGITALIZACIÓN \\
\hline & 01 & ISLA DE EDICIÓN MAC PRO EQUIPADA \\
\hline
\end{tabular}


TRANSMISIONES EN VIVO

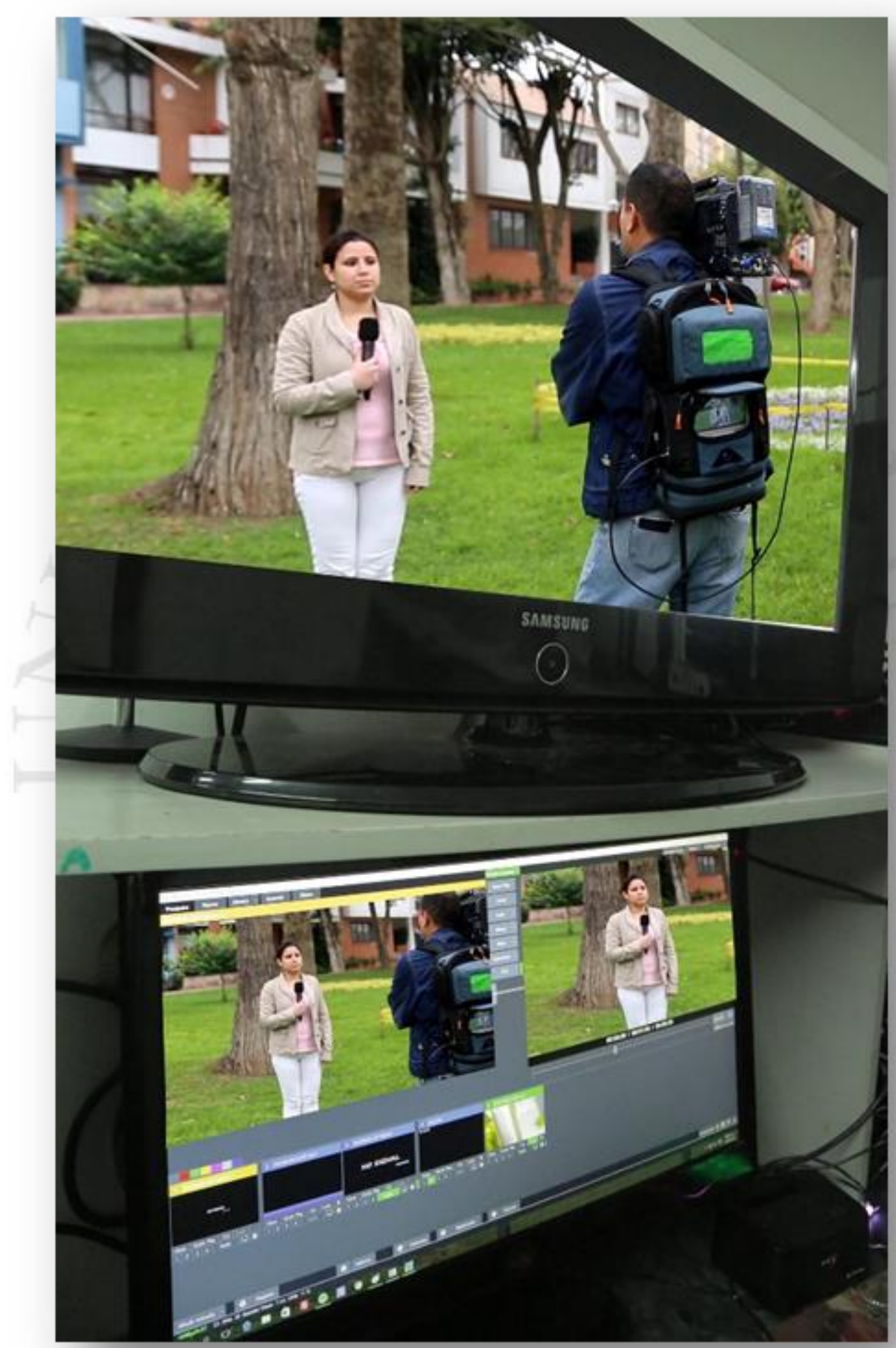




\section{DISEÑO DE UN CANAL WEB}

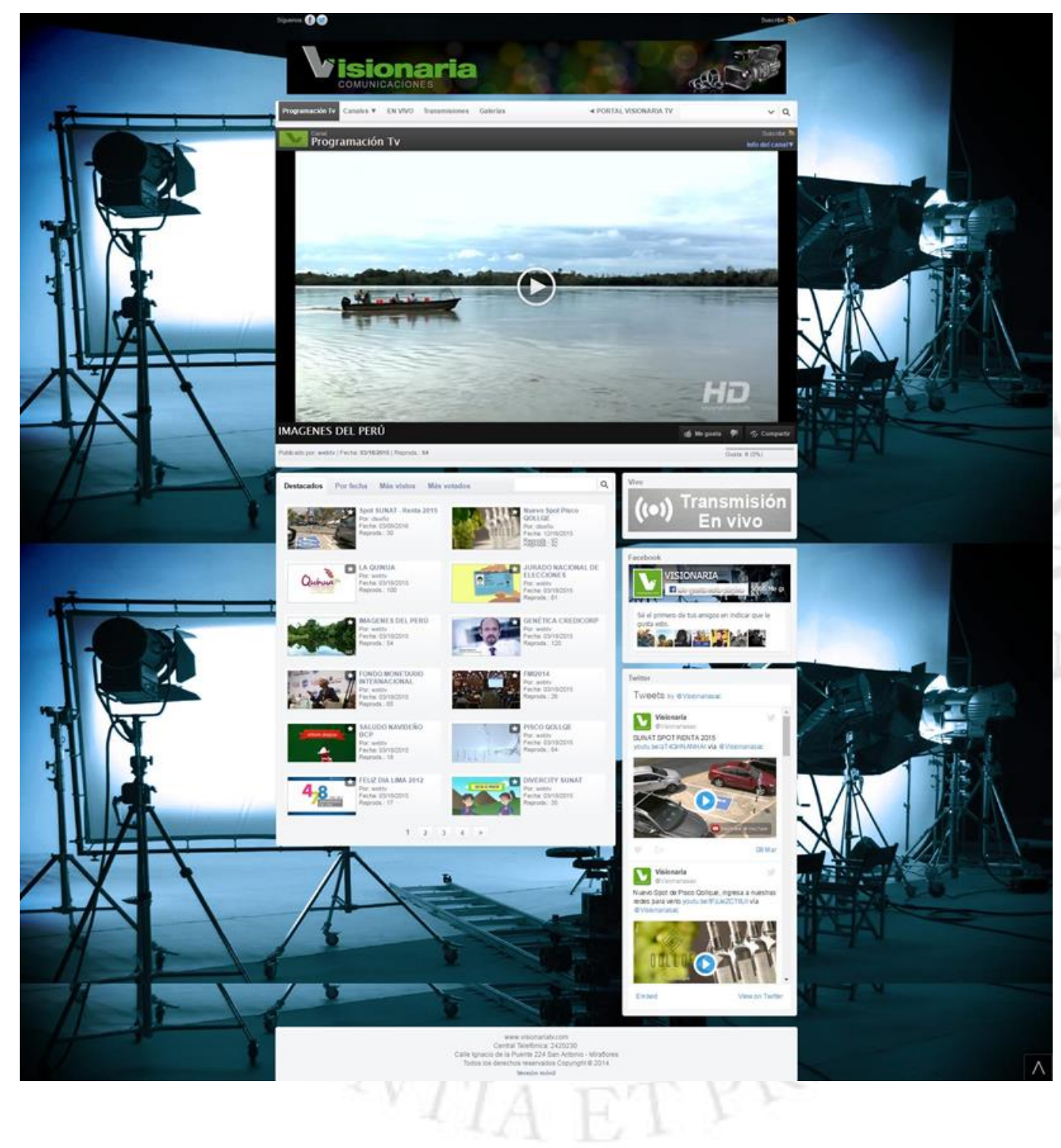




\subsubsection{Resultados obtenidos}

- Informar a la ciudadanía en tiempo real las actividades desarrolladas para el público consumidor peruano y extranjero.

Principales instituciones como ONPE, SUNAT, MINCETUR, CONGRESO DE LA REPUBLICA, BCP, TELEFONICA, AMERICA MOVIL, son unos de los clientes que apuestan por esta plataforma tecnológica, por ser una herramienta propia de la institución y no pública.

- A la fecha se ha logrado que cada institución transmita y publique su propio contenido, siempre bajo una supervisión y asesoría constante.

- Creación de la Asociación de Canales Web. ACWEP

\section{Canales web del Perú}
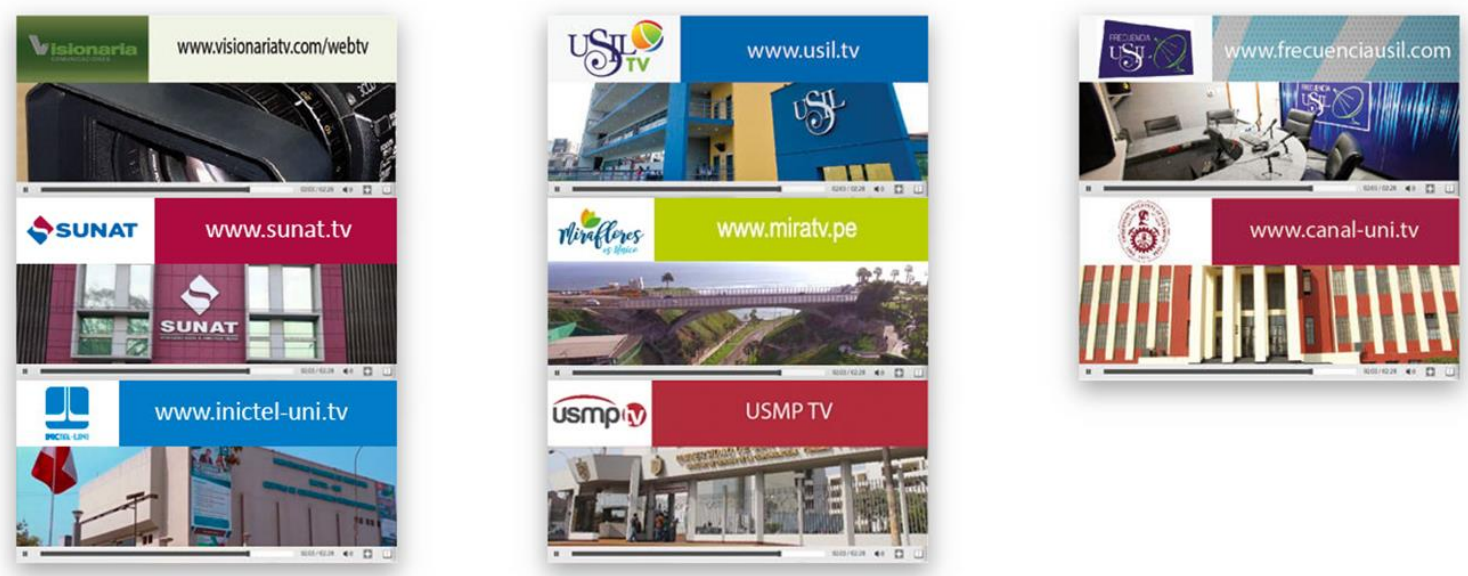

\subsubsection{Materiales producidos}

Se adjunta link de videos para su descarga

https://visionariatv.com/webtv/

www.canaleswebdelperu.com 


\section{REFLEXIONES PROFESIONALES}

La formación profesional me fue de gran ayuda para el desarrollo en las diferentes experiencias de trabajo que he realizado en la televisión peruana; en América Tv me gané el título de Primer Director de Tv en el Perú que tenía estudios universitarios y esto sirvió de ejemplo a los trabajadores y a los alumnos universitarios.

En mi larga trayectoria laboral, los cambios tecnológicos han impactado todos los estándares de sapiencia obtenida, es decir, la experiencia que obtuve en el cambio de señal abierta América Tv - C4, montar Cable Mágico televisión por cable fibra óptica, nunca se había visto esto en el país y fue toda una transformación que demoró adaptarse pero una vez que se logró fue un éxito tanto de cableros grandes como pequeños, logrando integrar señales internacionales y nacionales en su programación.

El montaje del Sistema CCTV del Banco de Crédito del Perú y la creación de Canal $\mathrm{BCP}$, así como la realización de contenidos y creación de su programación mensual, fue de mucha experiencia para mí, ya que era un sistema novedoso que ordenaba la atención al público y creaba un mejor servicio, una idea que muchas empresas del rubro imitaron, además de brindar una mayor comodidad para el cliente del banco, el sistema también logro promover todos los productos del banco y la ayuda social que el mismo brinda al país.

Los CCTV también fueron un gran desarrollo tecnológico y diferente que cubrió varias áreas de la televisión y comunicaciones, ya que se usó en muchos casos para difundir mensajes directos y ordenar la atención al público creándose una sub televisión institucional y empresarial, en muchas entidades.

Se logró mayor amicalidad entre funcionarios y clientes el Canal Bcp, sirvió de gran ayuda a las capacitaciones del personal del banco a nivel nacional, motivación que hizo avanzar y crecer junto a la modernidad, es decir llevarlo a la masificación en tiempo real vía internet, creando así los Canales Web del Perú.

En el montaje del Canal Bcp, la semiótica que estudie en la universidad, fue muy importante al aplicarla tanto en el diseño del sistema como en su operatividad de atención al cliente, así como en los contenidos que ahí se emiten, ayudando a crear el nuevo sistema de comunicación que el Banco tenía para con sus clientes, estudiando cada uno de los signos que se podrían presentar a lo largo 
de la implementación, evitando la generación de molestias por cualquier motivo para los clientes y/o visitas.

Para desarrollar los canales web del Perú, necesite poner en marcha todos los conocimientos y experiencia adquiridas en la TV convencional y CCTV desarrolladas para varios clientes, en sus diversos formatos SD, HD Y Full Hd desde sus inicios y que tras largos 10 años de esfuerzo y desarrollo en Visionaria SAC, se logró una señal HD por internet fluida, en la que el futuro de la tv logra tener su propio medio de comunicación para cada tema, institución o empresa, creándose una televisión dirigida a cada consumidor de manera selectiva además de usar computadoras, celulares, canales, etc. para poder verse, compartiendo esta programación con un código embed, el mismo que al embeberlo en canales de señal abierta y cable se puede ver en cualquier parte del mundo, ampliando de manera internacional la teleaudiencia incluidas la redes sociales.

Esto es la última revolución de las comunicaciones y a nivel mundial, los televidentes ven lo que desean ver en su pc, tv o celular y puedes transmitir en vivo con señal $\mathrm{Hd}$ embebible por cualquier canal de tv en el mundo. 


\section{RECOMENDACIONES A LOS EGRESADOS}

A. Es muy importante entender y estudiar bien la semiótica, te ayuda a lograr identificar aspectos del comportamiento humano que cualquier persona no se da cuenta, en sus diversos campos de acciones, ejemplo: hacer cola en un banco estaba desperdiciada el tiempo, al colocar el CCTV en cada agencia del Banco se logró captar la atención de todos los clientes manteniendo el orden en su atención.

B. En este mundo competitivo obtener el título de Licenciado de Comunicaciones, te abre muchas puerta a nivel laboral y/o comercial, las entidades públicas y/o privadas no solo evalúan la practica si no el nivel académico al que llegas, pudiendo realizar posteriormente alguna maestría, diplomado o MBA.

C. Lo que aprendí de esta carrera es que no existen las horas ni los días, es una forma de vida, la televisión es una pasión y hay que ser pasional para lograr triunfar en ella. 


\section{BIBLIOGRAFÍA}

Barthes, Roland (1971). Elementos de Semiología. Madrid. Alberto Corazón.

Dancyger, Ken (2019). The Technique of Film \& Video Editing (6 ed.). New Yorj. Rotuledge.

Eco, Umberto (1995). Tratado de semiótica general. Barcelona. Lumen.

Hepner, Harry (1962). Publicidad moderna principios y prácticas. Mexico. Uteha ed.

Saavedra, Manual (1992). Audiencias televisivas 1991 - Perú. Lima. Mercado Latino Ed. 


\section{ANEXOS}

\section{ANEXO 1: Título del anexo}

-Documentos sustentatorios de la hoja de vida:

constancias, certificados, contratos, etc...

-Otros documentos que se consideren necesarios para respaldar el informe.) 